\title{
IMPACT OF CYPERMETHRIN ON ALBUMEN GLAND OF FRESHWATER SNAIL, BELLAMYA BENGALENSIS
}

\author{
D. V. Ahirrao ${ }^{1}$ and S. R. Magare ${ }^{2}$ \\ 1 - PG Department of Zoology, S.S.V.P.S. L.K Dr. P. R. Ghogrey \\ Science College Dhule, M.S. India. \\ 2 - Arts, Science and Commerce College, Taloda. \\ Email ID : $\underline{\text { dv2ahirrao@gmail.com }}$
}

\begin{abstract}
Effect of sub lethal concentration of pyrethroid pesticides Cypermethrin on aquatic snail, Bellamya bengalensis was evaluated. The histochemical and biochemical analysis for 15 days exposed snail was made in the present work. The amount of biochemical components was greatly influenced in the range of $9.03 \%$ to $44.52 \%$ by Cypermethrin which causes depletion in glycogen level. The maximum depletion of glycogen content observed during the post-reproductive period after 15 days of exposure span.
\end{abstract}

Key words :- Cypermethrin, Bellamya bengalensis, Glycogen, Albumen gland.

\section{INTRODUCTION:}

Industrial and domestic effluents which account for the pollution that endangers the aquatic life contain various toxic substances. To combat these toxic effects and stress conditions organisms develop the necessary potential by altering energy metabolism. This results in severe changes in the metabolic cycles involving the inter change of biochemical constituents of tissues. When cells are stressed by an extreme environmental condition, they undergo a series of often irreversible biochemical and cellular changes and their study can give indications of the degree of a stress of the organism (Raghava Kumari, 2013).

Synthetic pyrethroids are more effective than other insecticides like carbamate and organophosphatase against several pests (Srivastava, 1996). Besides controlling hazardous insect pest population synthetic pyrethroids also affect several non-target organisms (Susan et. al., 1999).

Cypermethrin, a synthetic pyrethroid is a broadspectrum insecticide, used extensively in households and industrial and agriculture fields (Kakko et. al., 2003) for control of several insect pests. Due to indiscriminate use, cypermethrin makes their entrance into natural water bodies through agriculture run-off and ultimately affects the several non-target aquatic organisms; for instance, it inhibits growth and several metabolic activities of crustaceans (Li et. al., 2005), adversely affects fish metabolism and hematology and thus adversely affects fish meat quality and fish population (Adhikari et. al., 2004).

Singh and Agarwal (1990) and Tripathi and Singh (2001) showed that cypermethrin is also highly toxic against freshwater snail $L$. accuminata and also affects both their metabolism and reproduction.

Carbohydrates are the major source of energy for vital activities of organism. Glycogen is the stored food material in animal tissue which is used as an immediate source of energy when required and is an essential feature of the normal organism metabolism.

Singh et al., (2010) studied the effect of pyrethroids cypermethrin and deltamethrin on the snail Lymnaea acuminate.

The structure and function of the reproductive tract of snails and slugs have been studied with increasing interest in recent years. The functions of different reproductive organs have also been investigated (Ahirrao and Kulkarni, 2011; Ahirrao and Phand, 2013; Ahirrao and Borale, 2014; Ahirrao and Phand (2015 and 2017); Ahirrao (2018); Sonawane and Sonawane (2018). The present investigation deals with to investigate its biochemical changes in albumen gland due to Cypermethrin of the freshwater prosobranch snail, Bellamya bengalensis.

\section{MATERIAL \& METHODS :-}

The freshwater prosobranch snail, Bellamya bengalensis were collected from Aner Dam near Shirpur, Dist. Dhule, Maharashtra (India) and maintained in the laboratory condition for 
acclimation. $\mathrm{LC}_{50}$ values for 24 hours were determined by exposing the snails to pesticides cypermethrin during breeding season. A group of 25 animals were released into $0.005 \mathrm{ppm}$ cypermethrin concentration in water. After treatment the animals were sacrificed after 1,7 and 15 days of exposure during prereproductive, reproductive and post-reproductive periods and tissues like albumen gland were removed. The snails were subjected to pyrethroid, cypermethrin at 9.00 a.m. every time and were sacrificed only during morning hours between 8 to 9 a.m. in order to avoid changes in the concerned parameters due to circadian rhythms (Shankaraiah, 1978).

For biochemical estimations dry powder was used and its weight was kept practically constant through the experimental work. Glycogen was estimated by Kemp et.al. (1954). Experimental data was analysed statistically by adopting statistical method (Pillai and Sinha, 1968). Each value given here is the mean and standard deviation of three different preparations and each preparation was assayed three times. A variation was considered significant at $5 \%$ level of probability.

\section{RESULTS AND DISCUSSION:-}

The freshwater prosobranch snail, Bellamya bengalensis show the marked biochemical changes in tissues of albumen gland after 1,7 and 15 days of exposure during prereproductive, reproductive and post-reproductive periods.

In albumen gland the seasonal variation in the glycogen content due to cypermethrin intoxication resulted in its titre. A significant depletion in the glycogen level was found to be observed throughout the reproductive period.

After 1 day exposure maximum decrease was observed during pre-reproductive period (12.82\%, P < 0.05). A significant increase in glycogen content was observed during reproductive period after 1 and 7 days of exposure. The percentage decreased in glycogen content as compared to control ranges from $9.03 \%$ to $44.52 \%$. The maximum decrease was observed during post-reproductive period after 15 days of exposure $(44.52 \%, \mathrm{P}<0.001)$.

The albumen gland showed maximum amount of glycogen during pre-reproductive and reproductive periods while relatively low concentration was found during postreproductive period.

The above results showed that, in the albumen gland the glycogen content were initially increased during reproductive period and then decreased during exposure periods. The depletion of this metabolite content in this tissue during all periods was statistically significant after 1,7 and 15 days of exposure. (Table - 01; Fig. - 01)

In invertebrates the glycogen is most suitable reserve carbohydrate. The stored glycogen might be utilised for the formation of reproductive components and due to this the decrease in glycogen content during reproductive period (Kulkarni and Shinde 1992).

Lomte and Waykar (2000) and Sonawane and Lomte (2000) showed that the glycogen is the first metabolite to be used under stress conditions and decrease gradually during the entire exposure period. Disturbance in glycogen profile was considered as one of the most nutrible biochemical change due to action of pesticide.

The decrease in glycogen content suggests utilization to meet energy demands caused by toxic conditions. The decrease in glycogen would be due to decreased synthesis or increased utilization or the possibility of glycogenolysis. The constant decrease in glycogen was observed after 15 days of exposure to pyrethroids in all reproductive periods.

The results show that the glycogen is very sensitive marker of pyrethroid toxicity, in the sense that within one day of exposure considerable decrease in glycogen was noticed in all tissues. The glycogen is the first metabolite to be used under stress conditions, is found decrease gradually during the entire exposure span (Sonawane and Lomte, 2000; Lomte and Waykar, 2000; Magare and Patil, 2010; Ahirrao and Kulkarni, 2011; Ahirrao and Phand, 2013; Ahirrao and Borale, 2014; Ahirrao and Phand (2015 and 2017); Ahirrao (2018); Sonawane and Sonawane (2018).

Any stressful condition alters the biochemical composition. The change in metabolic rate leads towards the change in biochemical composition hence, the change in biochemical composition is an indicator of stress of chemical or physical nature in the surrounding which mainly affects glycogen contents.

\section{ACKNOWLEDGEMENT :-}

The authors are grateful to the President, Chairman and Principal, S.S.V.P.S.L.K. Dr. P. R. Ghogrey Science College, Dhule for providing necessary laboratory facilities and encouragement. 


\begin{tabular}{|l|c|c|c|c|}
\hline \multicolumn{1}{|c|}{ Period } & Control & 1 Day & 7 Day & 15 Day \\
\hline \multirow{3}{*}{ Pre- } & 18.72 & 17.03 & 16.10 & 11.80 \\
Reproductive & \pm 1.52 & \pm 1.22 & \pm 1.14 & \pm 1.33 \\
& & -9.03 & -13.99 & -36.96 \\
& & $*$ & $*$ & $* * *$ \\
\hline \multirow{3}{*}{ Reproductive } & 16.92 & 18.06 & 18.08 & 13.92 \\
& \pm 1.42 & \pm 1.33 & \pm 1.30 & \pm 1.40 \\
& & -6.73 & -6.85 & -17.73 \\
Post- & 14.89 & 12.98 & 12.10 & $*$ \\
Reproductive & \pm 1.28 & \pm 1.18 & \pm 1.80 & \pm 1.71 \\
& & -12.82 & -18.73 & -44.52 \\
& & $*$ & $*$ & $* * *$ \\
\hline
\end{tabular}

Table 1: Effect of Cypermethrin on Glycogen contents in Albumen gland of Freshwater snail, Bellamya bengalensis in $\mathrm{mg} \%$.

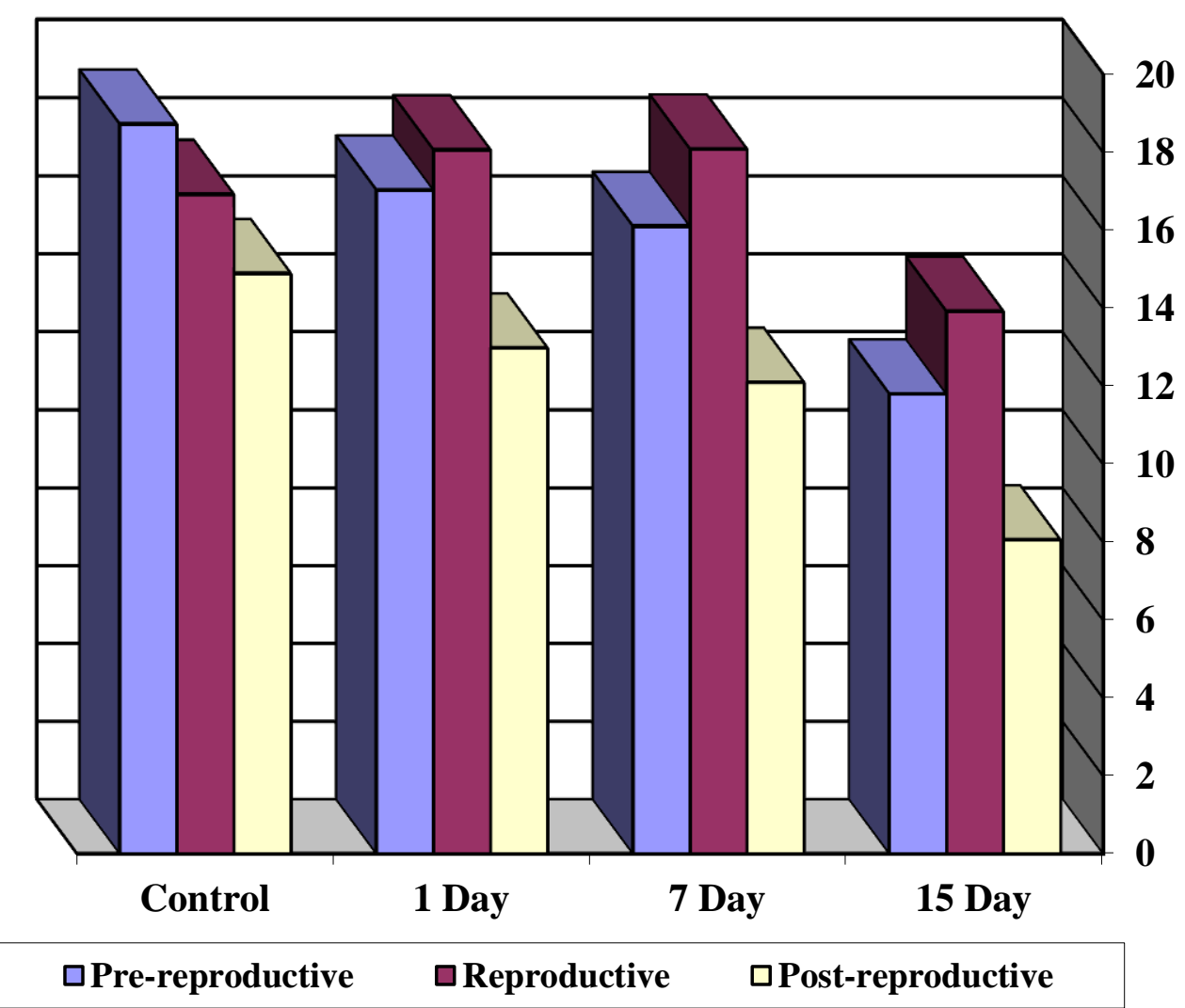

Fig. 1 : Effect of Cypermethrin on Glycogen contents in Albumen gland of Freshwater snail, Bellamya bengalensis in mg \%. 
REFERENCES:-

Adhikari S., Sarkar B., Chatterjee A., Mahapatra C.T., and Ayyappan S. (2004): "Effects of cypermethrin and carbofuran on certain hematological parameters and prediction of their recovery in a freshwater teleost, Labeo rohita (Hamilton)," Ecotoxicology and Environmental Safety, vol. 58, no. 2, pp. 220226.

Ahirrao D.V. and Kulkarni A.B. (2011): Sublethal Stress of Pyrethroids on Biochemical Contents in Prostate Gland of a Freshwater Snail, Bellamya bengalensis. Journal of Experimental Sciences; 2 (3) : 1-3.

Ahirrao D.V. and Phand D.L. (2013): Biomolecular changes in a snail, Bellamya bengalensis due to pyrethroid intoxication. International Journal of Biotechnology and Biosciences; 3(4):191-194.

Ahirrao K.D. and Borale R.P. (2014): Effect of Sevin on the glycogen content of fresh water snail, Thiara lineate. Scholarly Research Journal for Interdisciplinary Studies; 2(9): 19.

Ahirrao Dhairyashil V. and Deepak Phand L. (2015): Impact of cypermethrin on biochemical contents of a freshwater snail, Bellamya bengalensis. Journal of Experimental Biology and Agricultural Sciences; 3(1):10-14.

Ahirrao Dhairyashil V. and Deepak Phand L. (2017): Impact of fenvalerate on whole body of freshwater snail, Bellamya Bengalensis. International Journal of Applied Research; 3(1): 334-336.

Ahirrao Dhairyashil V. (2018): Impact of Fenvalerate on Biochemical Contents in Ovary of a Freshwater Snail Bellamya bengalensis. I J R B A T, Vol. VI (Special Issue 2), 01-08: 4-6.

Kakko I., Toimela T., and Tahti H. (2003): "The synaptosomal membrane bound ATPase as a target for the neurotoxic effects of pyrethroids, permethrin and cypermethrin," Chemosphere, vol. 51, no. 6, pp. 475-480.

Kemp A, Van Kits and Haijnilngen A.J.M. (1954): A calorimetric method for the determination of glycogen in tissues. Biochem J. $56: 646$.

Kulkarni, A.B. and Shinde, S.V. (1992) : seasonal variation in the glycogen content of freshwater Basommatophoran snail, Indoplanorbis exustus. J. Ecotoxicol. Environ. Monit., 2(2) : 145-147.

Li X., Ping X., Xiumei S., Zhenbin W. and Liqiang X. (2005): "Toxicity of cypermethrin on growth, pigments, and superoxide dismutase of Scenedesmus obliquus," Ecotoxicology and
Environmental Safety, vol. 60, no. 2, pp. 188192.

Lomte V.S, Waykar B.B. (2000): Effect of pesticide carbaryl, cypermethrin and endosulfan on glycogen content in different tissues of freshwater bivalve, Parreysia cylindrical. Environ. Issues and sustainable Development, Vinit Pub., Aurangabad. 4143.

Magare S.R, Patil R.D. (2010): Alterations in glycogen and protein contents in the freshwater fish, Barbus ticto due to toad poison. Journal of Chemo and Biosphere (I); 1:73-77.

Pillai, S.K. and Sinha, H.C. (1968): In statistical method for biological work. Ramprasad and Sons., Agra.

Raghava Kumari P. (2013): Detergent induced protein alterations in freshwater gastropod, Bellamya bengalensis (Lamarck). Indian J. Sci. Res. 4(1) : 57-60,

Shankaraiah, K. (1978): Study of environmental influences on some aspects of physiology of Barytelphusa guerini. Ph.D. thesis Osmania Uni., Hyderabad, India.

Singh A. and Agarwal R.A. (1990): "Molluscicidal properties of synthetic pyrethroids," Journal of Medicinal and Applied Malacology, vol. 2, pp. 141-144.

Sonawane S.M., Lomte V.S. (2000): Effect of molluscicide copper sulphate on lipid content of the bivalve, Lamellidens marginalis. Environ. Issues and Sustainable Development, Vinit Publ., Aurangabad, 3536.

Sonawane Sandhya M. and Mayur Sonawane (2018): Effect of heavy metal Copper sulphate on glycogen activity of Bivalve $L$. marginalis. IOSR Journal of Pharmacy: 8(7) II, PP. 21-27

Srivastava K.P. (1996): A Text Book of Applied Entomology, Kalyani Publisher, India, New Delhi.

Susan T.A., Veeraiah K. and Tilak K.S. (1999): “A study on the bio-accumulation of fenvalrate a synthatic pyrethroid, in the whole body tissues of Labeo rohita, Catla catla, Cirrhinus mrigala (Hamilton) by gas-liquid chromatography," Pollution Research, vol. 18, no. 1, pp. 57-59, 1999.

Tripathi P.K. and Singh A. (2001): "Toxic effect of alphamethrin (synthetic pyrethroid) on oxidative metabolism of the freshwater snail, Lymnaea acuminata," in Proceedings of the International Congress of Chemistry and Environment, S. L. Gargh, Ed., pp. 238-243, Indore, India. 